\title{
Effect of anticoagulant and antiplatelet agents on outcome of AV Fistula made for hemodialysis access
}

\author{
Yogi $N,{ }^{1^{*}}$ Baxi M, Baxi $J,{ }^{2}$ Acharya $G B,{ }^{3} \mathrm{Hazra}^{2} \mathrm{~K}^{3}$ \\ ${ }^{l}$ National Institute of Neurological and Allied Sciences, Kathmandu, Nepal, ${ }^{2}$ Fortis International Oncology Center, Noida \\ (U.P), India, ${ }^{3}$ Department of Surgery, Manipal College of Medical Sciences, Pokhara, Nepal
}

\author{
* Corresponding Author: \\ Dr. Nikunja Yogi \\ MBBS, MS (General Surgery) \\ Mch Resident (Neurosurgery) \\ National Institute of Neurological and Allied Sciences, \\ Kathmandu, Nepal \\ Email: yoginikunj@hotmail.com

\section{Citation} \\ Yogi N, Baxi M, Baxi J, Acharya GB, Hazra NK. Effect of \\ anticoagulant and antiplatelet agents on outcome of $\mathrm{AV}$ \\ Fistula made for hemodialysis access. Nepal Journal of \\ Medical sciences 2012;1(2):93-6.
}

\begin{abstract}
Background: Arteriovenous fistula (AVF) is the primary mode of achieving vascular access for hemodialysis in chronic renal failure (CRF). Because of high complication rates like thrombosis, maintenance of the fistula is a major challenge. Although antiplatelets and anticoagulants are emerging rapidly for improving the outcome of AVF but fear of bleeding, hematoma, subsequent compression of AV fistula and blockade restrict their use in many dialysis centers.
\end{abstract}

Methods: Seventy five patients for whom AVF was created for hemodialysis access from Feb 2005-April 2009 in Manipal Teaching Hospital, Pokhara, Nepal were included in a retrospective study. Analysis of results was done in two different age and sex matched groups; Group I had patients where no anticoagulants or antiplatelets were used and Group II had patients in which antiplatelets/anticoagulants were used.

Results: There were 27 patients in group I and 48 patients in group II. Both the groups were followed up till 2 years post operatively to check for the patency of the fistula. AV fistula was repeated in 16 cases altogether. In group II there were $5(10 \%)$ cases of repeat fistula while in group I it was repeated in $11(40 \%)$ cases.

Conclusion: Judicious use of antiplatelet/anticoagulant agents in cases of AVF for hemodialysis access can be beneficial in preventing the chances of occlusion of AVF and thus helps in its long term patency.

Keywords: Arteriovenous fistula; antiplatelet agents; anticoagulant agents; chronic renal failure

\section{Background:}

Ex of achieving vascular access for hemodialysis in patients with chronic renal failure and was first introduced in 1960 by Quinton-Scribner. ${ }^{1}$ Because of high complication rates like thrombosis, ${ }^{1-3}$ maintenance of vascular access for hemodialysis is a major challenge in care of hemodialysis patients. Autologous AVF introduced by Brescia and Cimino in 1966, overcame many of the problems of external dialysis shunts but thrombosis and blockage of fistula still remains an annoying problem in day to day practice of each vascular surgeon. ${ }^{4}$

Many of the predictors of fistula failure such as older age, female sex, black race, diabetes mellitus, obesity, and low blood pressure are controversial and not readily amenable to modification..$^{5-6}$ Preoperative vein mapping, use of the 
upper arm rather than forearm, intraoperative heparin administration, surgical ligation of vein branches, and transposition of deep fistulas to more superficial locations, are approaches that might increase the likelihood of attaining a successful fistula and have been recommended by several investigators. ${ }^{7-8}$ Although antiplatelets and anticoagulants are emerging rapidly for improving the outcome of AVF but fear of bleeding, hematoma, subsequent compression of $\mathrm{AVF}$ and blockade restrict their use in many dialysis centers.

This study analyses the effect of anticoagulant /antiplatelets given intra and postoperatively and intra-operative flushing of vein by heparin saline in improving the results of AVF created for hemodialysis access in patient with chronic renal failure (CRF).

\section{Methods:}

This is a retrospective analysis of results of AVF created for hemodialysis in CRF in a tertiary care center at western region of Nepal. Overall seventy five patients were included in the study for which AVF was created for hemodialysis access from Feb 2005-April 2009. Analysis of results was done in two different groups. Group I had patients where no anticoagulants and antiplatelets were used. Group II had patients in whom antiplatelets and anticoagulants were used both intraoperative and postoperatively. Patients who were already on antiplatelet or anticoagulants for any other conditions and those with abnormal coagulation profile on preoperative evaluation were excluded from the study.

All AVF were made under local anesthesia under complete aseptic precautions and intraoperative antibiotic. While in group I cases no antiplatetelets or anticoagulants were used intraoperatively and postoperatively, slight modification of technique was used in cases of group II for intraoperative administration of anticoagulants as well. In group II cases, an appropriate sized and patent vein was isolated. The distal end of it was ligated while the proximal end was cannulated with infant feeding tube. Heparin saline was flushed into the vein at regular intervals. This was done to check and maintain the patency of the veins as most of the veins are thrombosed because of either previous cannulations or due to coagulation disorders of uremia.

Fistula was made under a microscope with 7-0 to 9-0 prolene; the posterior layer of the fistula was taken first under vision with continuous sutures and then the anterior layer was completed. Heparin was given (subcutaneous 2500 units) intraoperatively just after finishing the anastomosis. In all radial fistulas Low molecular weight heparin (LMWH) was given (group II only) one or two doses depending on size of the vein anastomosed and the thrill palpable postoperatively.
Chances of thrombosis are less in brachial artery because of better flow, therefore anticoagulants can be avoided postoperatively in them unless any previous history of thrombosis is present or thrill is not well palpable. We usually prescribed LMWH for 2-3 days as per the thrill felt postoperatively and continued with clopidogrel or warfarin for 1-2 weeks especially in radial fistulas if thrill was not very prominent. Dosage was adjusted according to the renal function and the fistula function. We kept our patients admitted in our ward for 2-3 days for observation as blockade is most common in this period and our patients lived far away so that the course of fistula and the effect of LMWH and antiplatelets could be observed. We were not able to perform Doppler or preoperative vein mapping because of financial constraints of the patients.

Follow up was obtained every 3 months for a year and then every 6 months for at least a period of two years for each fistula made. Those patients who could not complete their follow up for at least first 3 months period were excluded from study. The fistula was labeled failure if there was evidence of thrombosis and blockage or if there was evidence of non-maturation at the end of 3 months and the decision of repeat fistula creation was taken thereafter. The number of repeat fistula was analyzed and taken as outcome measure for both the groups and their difference was analyzed using Chi-square test.

\section{Results:}

There were 27 patients in group I with 13 male and 14 female $(\mathrm{M}: \mathrm{F}=0.93)$ and 48 patients in group II with 27 male and 21 female $(\mathrm{M}: \mathrm{F}=1.29)$. The mean age in group I was 46.3 years ( age range of 12-71 years) and in group II was 42.5 years ( age range of 15-78 years). Both the groups were matched statistically in terms of age, sex and comorbidities (table 1).

Table 1: showing comparison of baseline characteristics of the groups

\begin{tabular}{lccc}
\hline \multicolumn{1}{c}{ Variables } & $\begin{array}{c}\text { Group I } \\
(\mathrm{n}=27)\end{array}$ & $\begin{array}{c}\text { Group II } \\
(\mathrm{n}=48)\end{array}$ & P value \\
\hline Age (Mean) & 46.3 & 42.5 & $0.32^{*}$ \\
Female sex & 14 & 21 & $0.66^{* *}$ \\
Hypertension & 19 & 29 & $0.54^{* *}$ \\
Diabetes & 9 & 17 & $0.86^{* *}$ \\
\hline
\end{tabular}

*t-test; **Chi-square test

Total number of fistula included in the study was 102 out of 75 cases including the repeat fistulas. Out of them 51 were Left Radial, 32 were Left Brachial, 10 were Right Radial and 9 were Right Brachial.

The outcome of the patients as compared by requirement of 
repeat fistula and bleeding is shown in table 2 .

Table 2: Showing comparison of outcome between the groups

\begin{tabular}{lcccc}
\hline outcome & & Group I & Group II & P value \\
\hline \multirow{2}{*}{ Repeated once } & + & 6 & 5 & \\
& - & 21 & 43 & 0.188 \\
Repeated twice & + & 3 & 0 & \\
& - & 24 & 48 & 0.043 \\
Repeated twice & + & 2 & 0 & \\
& - & 25 & 48 & 0.126 \\
bleeding & + & 1 & 1 & \\
& - & 26 & 47 & 1.000 \\
\hline
\end{tabular}

In our study we encountered two cases with bleeding among which one was from group I and the other from group II. Other complications were not seen in this study group.

\section{Discussion:}

Failure of AVF is a major problem in care of hemodialysis patients. The major causes of failure of fistula other than the technical causes are older age, female sex, black race, diabetes mellitus, obesity, and low blood pressure. ${ }^{9-12}$ Proper selection of the vein as determined by size of the vessel (more than $2.5 \mathrm{~mm}$ ), preoperative vein mapping to exclude thrombosed vessel preoperatively, surgical ligation of vein branches, and transposition of deep fistulas to more superficial locations, are approaches that might increase the likelihood of attaining a successful fistula. ${ }^{13-16}$

Although antiplatelet and anticoagulants are widely used nowadays for improving AVF outcome, specific guidelines has not been developed till date. There has been a divided opinion on the use of these agents and a lot of studies can be found on various databases which are done to look for the role of these agents in outcome of AVF.

The main reason against the use of these agents is fear of bleeding. A randomized controlled trial that examined the efficacy of combination therapy of aspirin and clopidogrel for prevention of arteriovenous graft failure was stopped before completion because the prevalence of hemorrhagic complication was significantly higher in the intervention group. ${ }^{17}$

Since both the drugs were not studied separately they could not conclude which of the two is more associated with bleeding. Aspirin is well known to increase the risk of gastrointestinal bleeding in the uremic population, ${ }^{18}$ but there have been no studies of the effects of clopidogrel on bleeding in this population. Bleeding and complication rate in our study was seen less even with use of anticoagulant/antiplatelet agent. In our study we had encountered only two cases with bleeding amongst which one had been given anticoagulant/antiplatelet agent (clopidogrel and subcutaneous LMWH) while no such drugs were used in other.

Few studies done before has shown similar results as ours suggesting a benefit of use of antiplatelet agents in making of an AVF. These agents were started 2-7 days prior to surgical creation of the fistula in their cases ${ }^{19-26}$ whereas we usually used LMWH intraoperatively and extend it for 2-3 days according to the thrill felt postoperatively and continue with aspirin or warfarin for 2-3 weeks postoperatively. Whereas there are studies which demonstrate no benefit of warfarin on preventing thrombosis in hemodialysis access..$^{27-30}$

The Dialysis Access Consortium trial also concluded that clopidogrel did not reduce the early failure of new fistulas ${ }^{31}$ unlike the results of our study. Thus, a thorough review of literature in use of anticoagulant and antiplatelet agents to improve the patency of AVF access leaves us with full of divided opinions and further studies are required to determine its efficacy and safety.

\section{Conclusion:}

Judicious use of antiplatelet/anticoagulant agents in cases of AVF for hemodialysis access may be beneficial in preventing the chances of occlusion of AVF and thus helps in its long term patency without significantly increasing the risk of bleeding.

\section{Conflict of interest: none}

\section{References:}

1. Quinton W, Dullard D, Scribner BH. Cannulation of blood vessels for prolonged hemodialysis. Trans Am Soc Art if Intern Organs 1960;6:104-13.

2. Rosenthal JJ: Vascular access for hemodialysis. Major Probl Clin Surg 1981;4:455-68.

3. Wilson SE, Stabile BE, Williams RA, et al. Current status of vascular access techniques. Surg Clin North Am 1982;62:531-51.

4. Brescia MJ, Cimino JE, Appel H, et al. Chronic hemodialysis using venipuncture and a surgically created arteriovenous fistula. N Engl J Med 1966;275:1089-92.

5. Prischl FC, Kirchgatterer A, Brandstatter E, et al. Parameters of prognostic relevance to the patency of vascular access in hemodialysis patients. J Am Soc Nephrol 1995;6:1613-8. 
6. Culp K, Flanigan M, Taylor L, et al. Vascular access thrombosis in new hemodialysis patients. Am J Kidney Dis 1995;26:341-6.

7. Silva MB, Hobson RW Jr 2nd, Pappas PJ, et al. A strategy for increasing use of autogenous hemodialysis access procedures: impact of preoperative noninvasive evaluation. J Vasc Surg 1998;27:302-7.

8. Malovrh M. Non-invasive evaluation of vessels by duplex sonography prior to construction of arteriovenous fistulas for hemodialysis. Nephrol Dial Transplant 1998;13:125-9.

9. Feldman HI, Held PJ, Hutchinson JT, et al. Hemodialysis vascular access morbidity in the United States. Kidney Int 1993;43:1091-6.

10. Miller PA, Tolwani A, Luscy P, et al. Predictors of adequacy of arteriovenous fistulas in hemodialysis patients. Kidney Int 1999;56:275-80.

11. Miller CD, Robbin ML, Allon M. Gender differences in outcomes of arteriovenous fistulas in hemodialysis patients. Kidney Int 2003;63:346-52.

12. Feldman HI, Joffe M, Rosas SE, et al. Predictors of successful arteriovenous fistula maturation. Am J Kidney Dis 2003;42:1000-12.

13. Robbin ML, Gallichio MH, Deierhoi MH, et al. US vascular mapping before haemodialysis access placement. Radiology 2000; 217: 83-8.

14. Allon M, Lockhart ME, Lilly RZ, et al. Effect of preoperative sonographic mapping on vascular access outcomes in hemodialysis patients. Kidney Int 2001;60:2013-20.

15. Beathard GA, Settle SM, Shields MW. Salvage of the nonfunctioning arteriovenous fistula. Am J Kidney Dis 1999;33:910-6.

16. Dixon BS, Novak L, Fangman J. Hemodialysis vascular access survival: upper-arm native arteriovenous fistula. Am J Kidney Dis 2002;39:92-101.

17. Kaufman JS, O'Connor TZ, Zhang JH, et al. Randomized controlled trial of clopidogrel plus aspirin to prevent hemodialysis access graft thrombosis. J Am Soc Nephrol 2003;14:2313-21.

18. Livio M, Benigni A, Vigano G, et al. Moderate doses of aspirin and risk of bleeding in renal failure. Lancet 1986;1:414-6.

19. Andrassy K, Malluche H, Bornefeld H, et al. Prevention of p.o. clotting of AV cimino fistulae with acetylsalicylic acid: results of a prospective double blind study. Klin Wochenschr 1974;52:348-9.

20. Janicki K, Dmoszynska A, Janicka L, et al. Influence of antiplatelet drugs on occlusion of arteriovenous fistula in uremic patients. Int Urol Nephrol 1992;24:83-9.

21. Michie D, Wombolt D. Use of sulfinpyrazone to prevent thrombus formation in arteriovenous fistulas and bovine grafts of patients on chronic hemodialysis. Curr Ther Res 1977;22:196-204.

22. Albert F. Prevention of early thrombus formation in arteriovenous fistulae. Dial Transplant 1981;10:167C$167 \mathrm{D}$.

23. Grontoft KC, Mulec H, Gutierrez A, et al. Thromboprophylactic effect of ticlopidinie in arteriovenous fistulas for hemodialysis. Scand J Urol Ncphrol 1985;19:55-7.

24. Grontoft KC, Larsson R, Mulec H, et al. Effects of ticlopidine in AV-fistula surgery in uremia. Fistula Study Group. Scand J Urol Nephrol 1998;32:276-83.

25. Fiskerstrand CE, Thompson IW, Burnet ME, et al. Double-blind randomized trial of the effect of ticlopidine in arteriovenous fistulas for hemodialysis. Artif organs 1985;9:61-3.

26. Janicki K, Janicka L, Dmoszynska A, et al. Effects of ticlopidine on platelet activity and occlusion of arteriovenous fistulas in IPD patients. Dial Transplant 1994;23: 576-9.

27. Crowther MA, Clase CM, Margetts PJ, et al. Low-intensity warfarin is ineffective for the prevention of PTFE graft failure in patients on hemodialysis: A randomized controlled trial. J Am Soc Nephrol 2002;13:2331-7.

28. Zellweger M, Bouchard J, Raymond-Carrier S, et al. Systemic anticoagulation and prevention of hemodialysis catheter malfunction. ASAIO J 2005;51:360-5.

29. Traynor JP, Walbaum D, Woo YM, et al. Low-dose warfarin fails to prolong survival of dual lumen venous dialysis catheters. Nephrol Dial Transplant 2001;16:645.

30. Mokrzycki MH, Jean-Jerome K, Rush H, et al. A randomized trial of minidose warfarin for the prevention of late malfunctions in tunneled, cuffed hemodialysis catheters. Kidney Int 2001;59:1935-42.

31. Dember LM, Beck GJ, Allon M, et al. Effect of clopidogrel on early failure of arteriovenous fistulas for hemodialysis: A randomized controlled trial. JAMA 2008;299:2164-71. 